\title{
Measuring diet quantity and quality dimensions of food security in rural Ethiopia
}

\author{
Degye Goshu*, Belay Kassa and Mengistu Ketema
}

School of Agricultural Economics and Agribusiness, Haramaya University, P.O. Box: 05, Haramaya University, Ethiopia.

Accepted 4 March, 2013

\begin{abstract}
Food insecurity is an overriding problem of most developing countries like Ethiopia, which requires empirical evidence pertinent to food security policy formulation and implementation. This paper investigates food security situation of households by surveying 260 farm households randomly and proportionately sampled from the major farming systems in Ethiopia. Households' daily calorie availability and dietary diversity were measured to capture the diet quantity and quality dimensions of food security of households. A seemingly unrelated regression (SUR) model results of the two measures suggested that the mean daily calorie intake per adult equivalent and dietary diversity level of households were about $1871 \mathrm{kcal}$ and 6.8 , respectively, with significant differences in farming systems and household idiosyncratic characteristics. The univariate probit model results show that the likelihood of households to be food security was $42.3 \%$, while their probability to have semi-diversified diet was $\mathbf{3 7 . 2} \%$. However, food security status and dietary diversity status were weakly interdependent and their determinant factors were significantly different. The major contribution of this paper is that it employs econometric estimation of dietary diversity scores and status and measures their interactions with diet quantity scales and food security status at household level.
\end{abstract}

Key words: Food security, dietary diversity, seemingly unrelated regression (SUR) model, bivariate probit.

\section{INTRODUCTION}

The main development objective of the Ethiopian Government is poverty eradication and the country's development policies and strategies are geared towards this end (MoFED, 2006; FDRE, 2012). Smallholder farming is the dominant livelihood activity for the majority of Ethiopians, but it is also the major source of vulnerability to poverty and food insecurity (Brown and Teshome, 2007). To combat this problem, the Ethiopian Government has designed food security policy and strategy which was first issued in 1996 within the framework of Ethiopia's Poverty Reduction Strategy (FDRE, 1996; FDRE, 2004). In this regard, agriculture is assumed to be a strong option for spurring growth, over- coming poverty, and enhancing food security. It is a vital development tool for achieving the Millennium Development Goals (MDG), one of which is to halve by 2015 the share of people suffering from extreme poverty and hunger (World Bank, 2008).

In the 1970s, definitions of food security emphasized a nation's aggregate food production but since then the focus is the ability of poor households to gain access to food in the necessary amounts. According to FAO (1996), food security is assumed to exist "when all people, at all times, have physical and economic access to sufficient, safe and nutritious food to meet their dietary needs and food preferences for an active and healthy life". The four 
dimensions of food security are food availability, stability of supply; accessibility of food, and quality and safety of food. Access, sufficiency, and quality are important aspects of the definition of food security which should be addressed by food security indicators.

In the literature, there are three categories of indicators of food security each with limited capacity to capture the extent of food security and hunger: Process, outcome, and trend indicators (Hoddinott, 1999). Household calorie acquisition and dietary diversity are the two basic outcome indicators of diet quantity. Diet quantity measures of this kind include daily food energy consumption per capita or per adult equivalent and percentage of households or people that are food energy-deficient (Radimer et al., 1990; FAO, 1996; Hoddinott, 1999; Swindale and Ohri-Vachaspati, 2005; Smith and Subandoro, 2007). If the estimated total energy in the food that the household acquires daily is lower than the sum of its members' daily requirements, the household is classified as food energy-deficient or commonly known as 'food insecure'.

On the other hand, the three basic indicators of diet quality are diet diversity, percentage of food energy from staples, and quantities of foods consumed daily per adult equivalent (Hoddinott, 1999; Smith and Subandoro, 2007; FAO, 2007; Kennedy et al., 2011). It might be quite possible to a household to meet its energy requirement but to be prevented from leading an active, healthy life of the household members due to deficiencies of other nutrients. Improved diet quality is associated with improved birth weight and child nutritional status and with reduced mortality (Ruel, 2002, 2003). It is, therefore, critically important that indicators of the nutritional quality of the food people eat are included in any analysis of food security. Diet diversity reflects how varied the foods typically consumed by a household are (Smith and Subandoro, 2007). Dietary diversity indicators based on food groups predict nutrient adequacy better than those based on individual foods (Ruel, 2002). The percentage of food energy acquired from staples at household level is measured as the percentage of dietary energy available from food staples in the total dietary energy available. A higher value indicates lower diet quality, because energy-dense starchy staples have small amounts of bio-available protein and micronutrients, leaving those consuming large amounts of them compared to other foods vulnerable to protein and micronutrient deficiencies (Smith and Subandoro, 2007).

In the latest theoretical and empirical literature of food security, there are about five methods of analyzing food security, each measuring different aspects of food security situation at different levels. The method of individual food intake data is used to measure diet quantity (calorie intake) of an individual in a household, while the method of household calorie acquisition is used to measure the same variable at household level
(Radimer et al., 1990; FAO, 1996; Swindale and OhriVachaspati, 2005; Smith and Subandoro, 2007). Dietary intake method, on the other hand, is used to measure the diet quality dimensions (nutritional content) of households or individuals (FAO, 2007; Smith and Subandoro, 2007; Kennedy et al., 2011). The United States Department of Agriculture (USDA) 18-item core module is being used recently in some countries of the world to measure diet quantity. This method categorizes households into three groups by their food security situation as 'food secure', 'food insecure without hunger', and 'food insecure with hunger' (Bickel et al., 2000). The method of index of household coping strategies is a measure of coping mechanisms based on how households adapt to the presence or threat of food shortages (Radimer et al., 1990; Maxwell and Frankenberger, 1992; Maxwell, 1996). This paper employs household calorie acquisition and dietary intake methods of food security analysis whereby moderate accuracy is maintained and misreporting is kept low (Hoddinott; 1999).

Empirical evidences on food security in Ethiopia indicate the prevalence of high level of food insecurity with significant idiosyncratic and spatial characteristics. There is much variation in household consumption patterns in Ethiopia, depending on specific geographical and sociocultural characteristics where calorie consumption is low, a high percentage of this consumption coming from cereals, and per capita intake of calories is relatively higher in rural than in urban areas (Guush et al., 2011). According to Samuel (2004), grain production and food security are not affected by the same factors but household size and age of the household head significantly determine household food security in Ethiopia. To achieve national food security in Ethiopia, it is necessary to improve market functioning, invest in infrastructure which reduces food transaction costs and provide incentives for increased production (Berhanu, 2004). For the period between 1989 and 1994, Block and Webb (2001) identified that households in Ethiopia which had initially more diversified income subsequently experienced a relatively greater increase in income and calorie intake. On the other hand, the analysis on the effects of food crisis in 2008 in Ethiopia shows broad deterioration of household food security (Hadleya et al., 2011). Rural income transfer programs (food-for-work and productive safety nets) in Ethiopia serve as temporary safety nets for food availability, but they are limited in boosting the dietary diversity of households and their coping strategies (Uraguchi, 2012). In addition to income transfer projects as determinants of household food security, socio-demographic variables of education and family size as well as agricultural input of land size are found to be significant in accounting for changes in households' food security due to these programs.

With regards to calorie adequacy, significant proportion $(45 \%)$ of rural households in the Amhara regional state of 
Ethiopia are food insecure (Freihiwot, 2007). Nearly 61\% of the sample household characterized by poor access to oxen, livestock and farm land in central Ethiopia (Eastern Shewa) are food insecure (Hailu, 2012). On the other hand, about $80 \%$ of households in Eastern Ethiopia are food insecure with food insecurity gap of 30\% (Zegeye and Hussien, 2011). But, Abebaw et al. (2011) estimates that $66 \%$ of the sampled households in this region of the country are food insecure, with food insecurity gap of $27 \%$. Food insecurity status of household in this region (Dire Dawa area) is significantly determined by family size, annual income, amount of credit received, access to irrigation, age of household head, farm size, and livestock owned (Bogale and Shimelis, 2009).

These specific food security studies generally suggest that depth and intensity of food insecurity is high, influenced by poor functioning of marketing systems and other household and socioeconomic factors. However, all the studies focused on one aspect of food security situation, specifically the percentage of households facing calorie shortage. To account for such shortcomings, the objectives of this study are to measure food security situations of households and identify their determinants and interactions in rural Ethiopia through two major outcome indicators of food security: Diet quantity and quality.

\section{RESEARCH METHODOLOGY}

\section{Sampling technique and the dataset}

This study used primary data collected from four districts selected from two major sedentary farming systems in Ethiopia, Central and Hararghe highlands. These two sedentary farming systems cover about $40 \%$ of the total sedentary farming systems in Ethiopia (Getahun, 1980; Dercon and Hoddinott, 2009). Because the study areas are heterogeneous in terms of their food security situation, two-stage stratified random sampling technique was employed. In the first stage, districts were stratified into two as highland and nonhighland. Two districts from highland areas were randomly selected from each farming system. In the second stage, kebeles - the lowest administrative levels - were stratified by their food security situation as better-off and worse-off. One kebele was randomly selected from each stratum.

Finally, a total of 260 rural households were randomly selected from eight kebeles proportionate to the number of households in each district and kebele. Because weights were given to farming systems, the samples were also proportionate at the two farming systems level. Stratification procedures at each stage were carefully employed to increase homogeneity within a food security stratum and heterogeneity between strata so that precision and sampling efficiency would be maximized. To overcome the problem of bias in collecting data on food security indicators, the survey was conducted in two phases depending on the harvesting periods and fasting months in the two farming systems. This timing of survey periods was expected to minimize the variability of household consumption prevalently observed to be skewed left and right during harvest and before harvest periods, respectively.

Methodologically, it is simple if continuous measures of food security are estimated. However, it is also often useful, both for policy and research purposes, to simplify the food security scale into a small set of categories, each one representing a meaningful range of severity on the underlying scale, and to discuss the percentage of the population in each of these categories. In this study, the measures of food security were treated as both continuous and categorical variables. A household was treated as either food secure or insecure based on its amount of calorie availability per adult equivalent, or may fall at a lower or higher level on the food insecurity continuum. Dietary diversity levels were measured from the counts of food items consumed by households. Households were also treated as having medium and low dietary diversity status depending on the number of food groups they consumed.

The endogenous variables used as food security indicators were daily calorie availability per adult equivalent, food security status, dietary diversity scores/levels, and dietary diversity status. These food security indicators were hypothesized to be primarily determined by a household's resource endowment. As such, the expected determinants of food security measures were categorized into five based on their resource endowment as humane capital (family size, farming experience, dependency ratio, literacy status, sex of the household head), social capital (degree of civic engagement and/or responsibility as a proxy for social networks and social class), physical capital (pattern of cultivated land allocation, livestock holding, number of oxen owned, total assets owned), financial capital (income earned, access to credit or amount of credit received), natural capital (irrigation water use, proportion of land under irrigation), and a dummy variable for the farming systems as a proxy to capture omitted location-specific characteristics (Table 1).

\section{Analytical methods}

Two groups of outcome measures of food security situation were estimated in this paper: the first is household calorie acquisition including daily calorie intake per adult equivalent to determine food availability and status of food security situation. The second outcome measure was dietary diversity to capture diet quality. Daily calorie availability can be measured in two ways, based on consumption per equivalent male adult and consumption based on age and sex without converting equivalent male adult. Food balance sheet and aggregate household calorie consumption were constructed for this purpose. Food security condition was estimated based on calorie requirement, according to sex, age, and activity level of household members, as recommended by FAO and WHO (1985).

Household calorie availability was computed from each food item consumed and grouped into seven food groups ${ }^{1}$, adjusted for food processing to obtain the net weekly calorie availability. The net weekly calorie availability was divided by seven to obtain the household daily calorie intake. The family size of each household was converted into adult equivalent family size which considers age, sex, and activity level of each family member in the household. The daily net calorie consumption of the household was divided by the adult equivalent family size to obtain the daily calorie availability per adult equivalent of the household. Households with daily calorie consumption greater than or equal to $2200 \mathrm{kcal}$ per day were categorized as 'food secure', and those households whose calorie intake fallen below this food security threshold grouped as 'food insecure'.

The association between household dietary diversity scores and dietary energy availability indicates that increasing household

\footnotetext{
${ }^{1}$ These food groups are (1) cereal, roots and tubers, (2) pulses and legumes, (3) dairy products (4) meats, fish and eggs (5) oils and fats, (6) fruits, and (7) vegetables.
} 
Table 1. Definition and notation of variables.

\begin{tabular}{|c|c|c|c|c|}
\hline \multirow[b]{2}{*}{ Variable name } & \multirow[b]{2}{*}{ Notation } & \multirow[b]{2}{*}{ Measurement } & \multicolumn{2}{|c|}{ Expected effect on food security indicators } \\
\hline & & & $\begin{array}{c}\text { Calorie intake } \\
\text { level/status }\end{array}$ & $\begin{array}{l}\text { Dietary diversity } \\
\text { level/status }\end{array}$ \\
\hline Daily calorie availability (log) & Incalav & Continuous & & \\
\hline Food security status & secur & Binary ( 1 if calav $>=2200,0$ otherwise) & & \\
\hline Household dietary diversity score & hdds 1 & Counts (food groups) & & \\
\hline Household dietary diversity score & hdds2 & Counts (food items) & & \\
\hline Household dietary diversity status & hds & Binary ( 1 if hdds $1>=4,0$ otherwise) & & \\
\hline Female heads & femal & Binary ( 1 if female, 0 otherwise) & \pm & \pm \\
\hline Family size & famsz & Continuous (head count) & - & - \\
\hline Child dependency ratio & depc & Continuous (\%) & - & - \\
\hline Literacy status & literat & Binary ( 1 if literate, 0 otherwise) & + & + \\
\hline Land cultivated & land & Continuous (ha) & + & + \\
\hline Land allocated to staples & landst & Continuous (ha) & + & + \\
\hline Irrigation water use & irrig & Binary ( 1 if user, 0 otherwise) & + & + \\
\hline Proportion of irrigated land & irrigp & Continuous (\%) & + & + \\
\hline Quantity of fertilizer & frtat & Continuous (qt) & + & + \\
\hline Livestock holding (TLU) & tlu & Continuous (tropical livestock unit) & + & + \\
\hline Annual gross income (log) & Ininom & Continuous (ETB) & + & + \\
\hline Social capital & social & Binary ( 1 if socially networked, 0 otherwise) & + & + \\
\hline Off-farm activity & ofarm & Binary ( 1 if participant, 0 otherwise) & + & + \\
\hline Distance to nearest road & road & Continuous $(\mathrm{km})$ & - & - \\
\hline Access to credit & credit & Binary (1 if participant, 0 otherwise) & + & + \\
\hline Production of major cash crop & mcash & Binary ( 1 if khat producer, 0 otherwise) & + & + \\
\hline Farming system & farmsy & Binary ( 1 if Hararghe highlands, 0 otherwise) & \pm & \pm \\
\hline
\end{tabular}

dietary diversity improves energy availability; but the reverse may not hold true (Hoddinott and Yohannes, 2002). Dietary diversity scores have potential for monitoring changes in dietary energy availability, particularly when resources are lacking for quantitative measurements. The association between dietary diversity and mean micronutrient density adequacy of complementary foods indicate the positive correlations in age groups (FANTA, 2006). Generally, dietary diversity scores have been shown to be valid proxy indicators for dietary energy availability at household level and micronutrient adequacy of diets of young children and women of reproductive age.

The seemingly unrelated regression (SUR) model representation of daily calorie intake per adult equivalent and household dietary diversity scores ${ }^{2}$ was employed to

${ }^{2}$ The number of food items is a count data. If there is overdispersion in the data, linear estimation of count data is assumed to result in inefficient, inconsistent, and biased parameter estimates. However, the count data model (Poison and negative binomial regression) results of dietary diversity scorers of food items were not largely simultaneously estimate the two linear outcome measure of food security situation of households (Zellner, 1962; Greene, 2012):

$\ln \operatorname{calav}_{i}=\mathbf{x}^{\prime} \boldsymbol{\beta}_{1}+\varepsilon_{1 i}$

different from the linear SUR model results because overdispersion was not detected. 
where $\ln$ calav $_{i}$ is the log of daily per adult equivalent calorie intake of household $i ; h d d s_{i}$ is household dietary diversity scores measured by the number of food items consumed per week; and $\mathbf{X}$ is a vector of factors determining daily calorie intake and dietary diversity level of households; $\boldsymbol{\beta}_{1}$ and $\boldsymbol{\beta}_{2}$ are the respective vectors of coefficients, $\varepsilon_{1 i}$ and $\varepsilon_{2 i}$ are their random terms.

Household and socioeconomic determinants of food security status and their likely effects were estimated by a univariate probit representation. The latent variable regression model for binary regression models was specified by the structural equation as (Maddala, 1983; Long, 1997; Cameron and Trivedi, 1998; Long and Freese, 2005; Cameron and Trivedi, 2009):

$\sec u r_{i}^{*}=\mathbf{x}^{\prime} \boldsymbol{\beta}+\varepsilon_{i}$

where $\sec u r_{i}^{*}$ is binary latent variable for food security status (observed if $\sec u r_{i}^{*}>0,0$ otherwise); $\mathbf{X}$ is a vector of household specific and other socioeconomic factors determining food security status; $\boldsymbol{\beta}$ is a vector of parameters of interest, and $\mathcal{E}_{i}$ random error.

The link between the observed binary $y$ and the latent $\sec u r_{i}^{*}$ is made with a simple measurement equation:

secur $r_{i}=\left\{\begin{array}{l}1 \text { if } \text { secur }_{i}^{*}=\mathbf{x}^{\prime} \boldsymbol{\beta}+\boldsymbol{\varepsilon}_{i}>0 ; \\ 0 \text { if secur } r_{i}^{*} \leq 0 .\end{array}\right.$

In addition to estimating the dietary diversity level of households, their dietary diversity status was determined from the frequency distribution of the number of food groups consumed and categorized into two as medium and poor dietary diversity status. This binary data was represented by a univariate probit model which is analogous to the model specified earlier to estimate the food security status of households in Equation (2).

The presence of bivariate interdependence between food security and dietary diversity status was tested by employing the bivariate probit model (Hardin, 1996; De Luca, 2008; Greene, 2012):

$\sec u r_{i}^{*}=\mathbf{x}_{1}^{\prime} \boldsymbol{\beta}_{1}+v_{1 i}$

$h d s_{i}^{*}=\mathbf{x}_{2}^{\prime} \boldsymbol{\beta}_{2}+v_{2 i}$

Where $\sec u r_{i}$, and $h d s_{i}$ are the food security status and the dietary diversity status, respectively; and $v_{1 i}$ and $v_{2 i}$ are their respective error terms in the seemingly unrelated bivariate probit and assumed to be normally distributed with ${ }^{*}\left[\left(\begin{array}{ll}0 \\ 0\end{array}\right)\left(\begin{array}{ll}1 & p \\ p & 1\end{array}\right)\right]$, where $\rho$ is the tetrachoric correlation between the latent variables.

Accordingly, the latent variables, observed and unobserved, were specified as:

$$
\begin{aligned}
& \text { secur }_{\mathrm{i}}= \begin{cases}\operatorname{secur}_{\mathrm{i}}^{*}=\mathbf{x}_{1}^{\prime} \boldsymbol{\beta}_{1}+\mathrm{v}_{1 \mathrm{i}} \text { if } \sec u r_{\mathrm{i}}^{*}>0 ; \\
0 & \text { if } \text { secur }_{\mathrm{i}}^{*} \leq 0 .\end{cases} \\
& h d s_{i}= \begin{cases}h d s_{i}^{*}=\mathbf{x}_{2}^{\prime} \boldsymbol{\beta}_{2}+v_{3 i} & \text { if } h d s_{i}^{*}>0 \\
0 & \text { if } h d s_{i}^{*} \leq 0\end{cases}
\end{aligned}
$$

\section{RESULTS AND DISCUSSION}

\section{Data description}

Two important dimensions of food security were analyzed through two basic indicators of food security: diet quantity and diet quality. The dichotomous classification of households based on their daily calorie availability suggested that $42.7 \%$ of the households were food secure, while the rest majorities (57.3\%) were food insecure or calorie-deficient. The frequency distribution of counts of food items suggested that most households consumed five kinds of food items grouped under three food categories. The binomial classification of households by their level of diet diversity into two status as 'medium diversity' and 'low diversity' showed that only $40 \%$ of the households consumed more than three food groups, suggesting that the rest majority faced low diet quality.

The estimated income and consumption inequalities among households were decomposed into their constituent income and calorie sources as reported in Table 2. The consumption inequality measured by the Gini coefficient was 0.21 and 0.22 , respectively, in Central and Hararghe highlands which are nearly similar to the 0.27 national rural consumption inequality estimated in the year 2010/11 (FDRE, 2012). The four food groups used as major sources of household calorie consumption were cereals, roots, and tubers, pulses and legumes, livestock products, and fats and oils. Consumption of cereals, roots and tubers and oils and fats were household calorie sources enabling to reduce consumption inequality in rural Ethiopia. As expected in developing countries, the estimated share in total inequality suggested that consumption inequality was predominantly contributed by consumption of cereal, roots and tubers. The marginal effects indicated that a unit percentage increase in consumption of cereals, roots and tubers reduced consumption inequality by about $0.06 \%$. However, consumption on pulses and legumes and livestock products was source of consumption inequality. On the other hand, the sample households had total income inequality of about 0.45 , higher than the national rural income inequality estimated in the same period (0.30), while it was lower in Central highlands (0.38) but higher in Hararghe highlands (0.52). This income inequality was twofold higher than the consumption inequality. Production of crops seems the sole determinant of income inequality in both farming systems. A unit percentage increase in crop income reduced total income inequality by about $1.4 \%$.

\section{Diet quantity and diversity levels}

Assuming that daily calorie availability is correlated with 
Table 2. Decomposition of income and consumption inequalities by farming systems (marginal effects).

\begin{tabular}{lccc}
\hline \multirow{2}{*}{ Source } & \multicolumn{3}{c}{ Marginal effects (\% change) } \\
\cline { 2 - 4 } & Central highlands & Hararghe highlands & All \\
\hline Total calorie (Gini) & 0.208 & 0.219 & 0.222 \\
Cereal, roots and tubers & -0.049 & -0.077 & -0.061 \\
Pulses and legumes & -0.007 & 0.031 & 0.016 \\
Livestock products & 0.004 & 0.013 & 0.012 \\
Oils and fats & -0.006 & 0.033 & -0.001 \\
Total income (Gini) & 0.380 & 0.522 & 0.446 \\
Crop income (Gini) & -2.160 & -0.799 & -1.393 \\
Livestock income & 0.000 & 0.000 & 0.000 \\
Off-farm income & -0.129 & -0.788 & -0.501 \\
\hline
\end{tabular}

Source: Authors' computation (2012).

Table 3. Simultaneous estimation results of daily calorie availability and dietary diversity.

\begin{tabular}{|c|c|c|}
\hline \multirow{2}{*}{ Equations and variable } & \multicolumn{2}{|c|}{ Coefficients } \\
\hline & Daily calorie availability & Dietary diversity scores \\
\hline Female heads & $0.13^{*}$ & $0.90^{* * *}$ \\
\hline Family size & $-0.05^{\star * *}$ & -0.01 \\
\hline Literacy status & $0.10^{\star *}$ & $1.21^{* * *}$ \\
\hline Land cultivated & $0.16^{* *}$ & -0.08 \\
\hline Land allocated to staples & -0.08 & 0.16 \\
\hline Irrigation water use & $-0.18^{* \star *}$ & $-0.46^{*}$ \\
\hline Quantity of fertilizer & $0.08^{* \star *}$ & 0.24 \\
\hline Livestock holding (TLU) & 0.003 & $0.12^{* *}$ \\
\hline Annual gross income (log) & 0.06 & $0.74^{\star \star *}$ \\
\hline Off-farm activity & $-0.14^{\star \star *}$ & 0.02 \\
\hline Distance to nearest road & $-0.02^{* \star *}$ & -0.01 \\
\hline Farming system & 0.05 & $3.72^{\star \star \star}$ \\
\hline Constant & $7.22^{* \star *}$ & $-2.94^{*}$ \\
\hline$R^{2}$ & 0.2746 & 0.4948 \\
\hline Predicted value $\left(e^{7.54}\right)$ & 1878.71 & 6.77 \\
\hline Predicted value (Hararghe highlands) & 1828.13 & 8.92 \\
\hline Predicted value (Central highlands) & 1916.69 & 5.19 \\
\hline Predicted value (literate) & 1990.57 & 7.46 \\
\hline Predicted value (illiterate) & 1798.26 & 6.25 \\
\hline Cross-equation correlation of residuals & \multicolumn{2}{|c|}{0.20} \\
\hline Breusch-Pagan test of independence & \multicolumn{2}{|c|}{0.001} \\
\hline
\end{tabular}

***, ${ }^{* *}$ and ${ }^{*}$, respectively, signify significance levels of 1, 5 and 10\%. Source: Authors' computation (2012).

dietary diversity scores of food items, underlying common determinants of food security measures were identified by estimation of the linear SUR model of the two equations. The cross-equation correlation of residuals was strongly significant at $1 \%$ level and the null that the two equations are independent was rejected, suggesting that their simultaneous estimation was appropriate (Table 3). About 27.5 and $49.5 \%$ of the variation, respectively, in daily calorie availability and dietary diversity scores of food items were explained by the SUR model. The SUR model results demonstrated that the determinants enhancing daily calorie availability were female heads, literacy status, land cultivated, quantity of chemical fertilizer used, and other shocks captured by the constant term, all of which were in line with the expectations depicted in Table 1 (Hoddinott, 1999; Kennedy et al., 2011). Factors adversely affecting households' daily calorie availability were family size, irrigation water use, participation in off-farm activity, and road distance. The negative effect of off-farm activity on food security reflects the Ethiopian context in the farming systems for the fact that most households engaged in commercial and other 
Table 4. Univariate probit estimation of determinants of household food security status.

\begin{tabular}{|c|c|c|c|c|}
\hline \multirow{2}{*}{ Determinant } & \multirow{2}{*}{$\begin{array}{c}\text { Coefficients } \\
\text { (secure=111) }\end{array}$} & \multicolumn{3}{|c|}{ Marginal effects } \\
\hline & & All & Hararghe highlands & Central highlands \\
\hline Female heads & $0.45^{\star}$ & $0.18^{*}$ & $0.18^{*}$ & $0.18^{*}$ \\
\hline Family size & $-0.14^{\star \star \star}$ & $-0.06^{* * *}$ & $-0.06^{\star * *}$ & $-0.06^{* * *}$ \\
\hline Land cultivated & $0.73^{* * *}$ & $0.28^{* * *}$ & $0.28^{* * *}$ & $0.29^{* * *}$ \\
\hline Land allocated to staples & $-0.66^{\star *}$ & $-0.26^{\star *}$ & $-0.25^{\star *}$ & $-0.26^{\star *}$ \\
\hline Irrigation water use & $-0.56^{* * *}$ & $0.21^{* * *}$ & $-0.20^{* * *}$ & $-0.21^{* * *}$ \\
\hline Quantity of fertilizer & $0.30^{*}$ & $0.12^{*}$ & $0.12^{*}$ & $0.12^{*}$ \\
\hline Livestock holding (TLU) & 0.03 & 0.01 & 0.01 & 0.01 \\
\hline Annual gross income & $0.24^{*}$ & $0.09^{*}$ & $0.09^{*}$ & $0.09^{*}$ \\
\hline Off-farm activity & -0.26 & -0.10 & -0.10 & -0.10 \\
\hline Access to credit & $0.41^{*}$ & $0.16^{*}$ & $0.16^{*}$ & $0.16^{*}$ \\
\hline Farming system & -0.16 & -0.06 & -0.06 & -0.06 \\
\hline Constant & -1.95 & & & \\
\hline Predicted probability (all) & & 0.423 & 0.388 & 0.449 \\
\hline Predicted probability (with irrigation) & & 0.270 & 0.241 & 0.292 \\
\hline Predicted probability (without irrigation) & & 0.480 & 0.444 & 0.506 \\
\hline Predicted probability (with credit) & & 0.559 & 0.523 & 0.585 \\
\hline Predicted probability (without credit) & & 0.397 & 0.362 & 0.423 \\
\hline Log likelihood & & 145.06 & & \\
\hline Pseudo $R^{2}$ & & 0.18 & & \\
\hline
\end{tabular}

${ }^{* \star *},{ }^{* \star}$, and ${ }^{*}$, respectively, signify significance levels of 1, 5 and $10 \%$. Source: Authors' computation (2012).

off-farm activities are those which are less food secure and resource-deficient. They use off-farm activities as a coping strategy to overcome their food insecurity situation. On the other hand, factors enhancing diet diversity were female heads, literacy status, livestock holding, annual gross income, and the farming system in which the households operate. Factors adversely affecting diet diversity were irrigation water use and other exogenous shocks. In terms of magnitude, the most important determinants were the farming system followed by literacy status and female-headed households. With the exception of irrigation water use, the factors of daily calorie intake and dietary diversity scores were generally in line with the empirical evidences in Ethiopia by Birhanu and Moti (2010), Moti and Gardebroek (2008), Adane (2009), and Mamo et al. (2009).

The predicted values of daily calorie availability per adult equivalent and number of food items consumed were 1878.7 and 6.8, respectively. However, households' daily calorie availability and dietary diversity scorers were significantly different between households in the two farming systems and between their literacy statuses. Households in Central highlands, on average, obtained relatively higher daily calorie (1916.7 kcal) per adult equivalent and lower number of food items (5.2) a week as compared to their counterparts in Hararghe highlands, which obtained some $1828.1 \mathrm{kcal}$ and 8.9 number of food items. The results generally indicated that households in
Central highlands were relatively better-off in their daily calorie availability and worse-off in their dietary diversity. The role of literacy status in enhancing the likelihood of food security and dietary diversity was relatively higher (1990.6 kcal and 7.5 food items) than that of illiterate households ( $1798.3 \mathrm{kcal}$ and 6.3 food items).

\section{Diet quantity and diversity status}

Households' food security status was estimated by a univariate probit model and the results reported in Table 4. Food security status was significantly enhanced by female heads, cultivated land, quantity of chemical fertilizer used, annual gross income, and access to credit. However, their food security status was adversely affected by family size, land allocated to staples, and irrigation water use. The negative effect of irrigation water use can be explained by the prevalent situation most parts of Ethiopia that households with irrigation water access were promoted to produce crops more demanded in the market (cash crops) and the risk involved in the marketing of these crops was eventually harming their food security status.

The marginal effects and the associated probabilities were computed at different combinations of the farming systems, irrigation water use, and credit access. Food security status of households was predominantly 
Table 5. Univariate probit estimation of determinants of household dietary diversity status.

\begin{tabular}{|c|c|c|c|c|}
\hline \multirow{2}{*}{ Determinant } & \multirow{2}{*}{ Coefficients } & \multicolumn{3}{|c|}{ Marginal effects } \\
\hline & & All & Hararghe highlands & Central highlands \\
\hline Female heads & 0.12 & 0.05 & 0.04 & 0.03 \\
\hline Family size & 0.02 & 0.01 & 0.01 & 0.01 \\
\hline Literacy status & $0.47^{\star \star *}$ & $0.18^{* * *}$ & $0.16^{\star \star *}$ & $0.12^{\star *}$ \\
\hline Land cultivated & 0.09 & 0.03 & 0.03 & 0.02 \\
\hline Irrigation water use & -0.22 & -0.08 & -0.08 & -0.05 \\
\hline Quantity of fertilizer & -0.11 & -0.04 & -0.04 & -0.03 \\
\hline Livestock holding (TLU) & $0.11^{\star \star *}$ & $0.04^{* * *}$ & $0.04^{\star \star *}$ & $0.03^{* * *}$ \\
\hline Annual gross income (log) & $0.41^{\star * *}$ & $0.15^{\star * *}$ & $0.14^{\star * *}$ & $0.10^{* * *}$ \\
\hline Off-farm activity & -0.10 & -0.04 & -0.03 & -0.02 \\
\hline Access to credit & -0.13 & -0.05 & -0.04 & -0.03 \\
\hline Distance to nearest road & -0.04 & -0.01 & -0.01 & -0.01 \\
\hline Farming system & $1.57^{* * *}$ & $0.54^{* * *}$ & $0.54^{\star \star *}$ & 0.54 \\
\hline Constant & $-5.40^{\star \star \star}$ & & & \\
\hline Predicted probability (all) & & 0.372 & 0.708 & 0.167 \\
\hline Predicted probability (literate) & & 0.477 & 0.792 & 0.243 \\
\hline Predicted probability (illiterate) & & 0.299 & 0.635 & 0.122 \\
\hline Log likelihood & \multicolumn{4}{|c|}{-135.04} \\
\hline $\operatorname{LR} \chi^{2}(12)$ & \multicolumn{4}{|c|}{79.89} \\
\hline Pseudo $R^{2}$ & \multicolumn{4}{|c|}{0.23} \\
\hline
\end{tabular}

${ }^{* * *},{ }^{* *}$, and *, respectively, signify significance levels of 1, 5 and 10\%. Source: Authors' computation (2012).

increased by total cultivated land $(28 \%)$, female heads $(18 \%)$, access to credit $(16 \%)$, quantity of fertilizer used $(12 \%)$, and annual income (9\%). Their food security status was mainly decreased by land allocated to staples $(26 \%)$, irrigation water use (21\%), and family size $(6 \%)$. The huge and negative marginal effect of land allocated to production of staples suggests that households land allocation to staples could not lead to better food security situation unless optimum land allocation decisions are made. However, the marginal probabilities of households to be food secure in the two farming systems were not largely different.

The likelihood of households to be food secure was about $42.3 \%$, but lower for households in Hararghe highlands (38.8\%) as compared to the likelihood of their counterparts in Central highlands (44.9\%). These results are consistent with the SUR model results since households' food security status in Central highlands was relatively better-off, even if they were relatively worse-off in their dietary diversity. Households using irrigation water had lower probability to be food secure $(27 \%)$ compared to those households without irrigation (48\%). This negative effect was relatively lessened in Central highlands. But, credit access was relatively more consequential in enhancing food security of households $(55.9 \%)$ compared to those households without credit $(39.7 \%)$. This scenario was verified in both farming systems where households with credit access in Central highlands were more probably foods secure $(58.5 \%)$ and those without credit less probably food secure (42.3\%). Credit access was relatively more effective in improving household food security in Central highlands.

Households' diet diversity status was estimated by a univariate probit model as reported in Table 5. The factors determining households' diet diversity were literacy statuses, livestock holding, annual income, farming system, and the constant term (negatively). The probability of households to diversify their diet quality was largely increased by the farming system (54\%) followed by literacy status (18\%) and annual income (15\%). The likelihood of households to have semi-diversified diet was $37.2 \%$, but higher for those in Hararghe highlands $(70.8 \%)$ and lower in Central highlands (16.7\%). Literate households had higher probability of having better diet diversity $(47.7 \%)$ compared to the illiterate ones (29.9\%). The role of literacy status was also different in the two farming systems as indicated by the predicted probabilities in Hararghe $(79.2 \%)$ and Central highlands $(24.3 \%)$, suggesting that food security effects of literacy was more pronounced in Hararghe highlands.

The expected interdependence of food security status and dietary diversity status was disproved by employing the bivariate probit estimation of the two equations (Table 6 ). The null that food security status and dietary diversity status are independent was accepted since their tetrachoric correlation was weak (13\%). Unlike the SUR 
Table 6. Bivariate probit estimation of food security and dietary diversity status.

\begin{tabular}{|c|c|c|}
\hline \multirow{2}{*}{ Variable } & \multicolumn{2}{|c|}{ Coefficients (Equations) } \\
\hline & Food security equation & Dietary diversity equation \\
\hline Female heads & $0.56^{* \star}$ & 0.12 \\
\hline Family size & $-0.14^{\star \star \star}$ & 0.02 \\
\hline Literacy status & 0.25 & $0.46^{\star \star *}$ \\
\hline Land cultivated & $0.67^{* * *}$ & 0.09 \\
\hline Land allocated to staples & $-0.57^{\star *}$ & - \\
\hline Irrigation water use & $-0.69^{* * *}$ & -0.21 \\
\hline Quantity of fertilizer & $0.29^{\star \star}$ & -0.11 \\
\hline Livestock holding (TLU) & 0.03 & $0.11^{\star \star *}$ \\
\hline Annual gross income (log) & 0.23 & $0.42^{\star \star \star}$ \\
\hline Off-farm activity & $-0.32^{*}$ & -0.10 \\
\hline Access to credit & $0.42^{* *}$ & -0.12 \\
\hline Production of major cash crop & -0.37 & - \\
\hline Distance to nearest road & $-0.04^{*}$ & -0.04 \\
\hline Farming system & - & $1.51^{* * *}$ \\
\hline Constant & -1.82 & $-5.45^{\star \star \star}$ \\
\hline Athrho, $\hat{\rho}$ & \multicolumn{2}{|c|}{0.19} \\
\hline Rho, $\rho$ & \multicolumn{2}{|c|}{0.19} \\
\hline Log pseudo likelihood & \multicolumn{2}{|c|}{-275.541} \\
\hline Wald $\chi^{2}(25)$ & \multicolumn{2}{|c|}{133.76} \\
\hline Wald test of rho $=0: P>\chi^{2}(1)$ & \multicolumn{2}{|c|}{0.13} \\
\hline
\end{tabular}

Food security status and dietary diversity status are not significantly interdependent, which suggests that reporting of joint marginal effects is less important. ${ }^{* *},{ }^{* *}$, and ${ }^{*}$, respectively, signify significance levels of 1,5 and $10 \%$. Source: Author's computation (2012).

model results, the bivariate probit representation of the two equations suggested that food security status and dietary diversity status were not significantly interdependent and their univariate estimation was correct. Food security status and dietary diversity status had no common underlying determinants in rural Ethiopia. Though there is strong and positive interdependence between the two linear measures of food security scales, the interdependence between nonlinear measures of diet quantity and quality is very weak. This result suggests that nonlinear measures of diet quantity and quality aspects of household food security in rural Ethiopia were determined by different factors.

To verify the reliability of the negative effects of irrigation water access on food security situation, households' crop choice and other relevant indicators were further investigated with households' status of irrigation water access. The mean comparison test of crop choices as measured by their land allocation suggested that the mean values of most crops chosen by households were significantly different between irrigation water users and nonusers. Nonusers allocated relatively more land to staples (sorghum, wheat, barley, and horse bean) and less risky cash crops like khat, while irrigation water users allocated relatively more land to more risky perishable cash crops (carrot and onions) and less productive cash crops like fenugreek. There was no significant difference between households with and without irrigation water in their land allocation to other crops. This evidence verifies that own production of food was an integral component of smallholders' food security in Ethiopia. There should be innovation and introduction of productive, high value and less-risky cash crops from which households can choose. Moreover, households with irrigation water access should be promoted to engage in the production of such crops. In the existing situation in Ethiopia, the debate on ability of a smallholder-dominated subsistence farm economy to diversify into riskier, high-value crops is intuitive (Birthal et al., 2007; Birhanu et al., 2007; Samuel and Sharp, 2007; Hendriks and Msaki, 2009; Birhanu and Moti, 2010; Langat et al., 2011).

The mean daily calorie intake of irrigation water users was only $1870 \mathrm{kcal}$, which is relatively lower compared to the daily calorie intake by nonusers $(2107 \mathrm{kcal})$. About $70 \%$ of the food insecure households were users of irrigation water. About $65 \%$ of the households who 
participated in crop output markets were irrigation water users, which verify their engagement in the production and marketing of relatively more marketable crops. However, this does not mean that irrigation water use, ceteris paribus, adversely affects food security situation. Rather, irrigation water users were relatively less food secure because their crop mix and diversification and commercialization patterns were changed when they used irrigation water. Their increased market participation was not supported by better scale of crop diversification to cope up with the additional risk they most likely faced when they participated in the output markets. Irrigation users were less likely to produce staples (food crops) and more likely to face market risk and to be calorie-deficient. In addition, the negative effect of irrigation water use on food security situation was verified by many empirical evidences specifically in areas where market risk is pronounced (Birhanu et al., 2007; Birhanu and Moti, 2010).

\section{CONCLUSIONS AND POLICY IMPLICATIONS}

Food insecurity in Ethiopia, like most developing countries, is an overriding problem of development policy agenda. A number of empirical studies conducted on the subject have proven that food security policies and intervention mechanisms require relevant and inclusive empirical evidence on factors related to poverty reduction and enhancement of food security. This study profoundly examines the food security situation of farm households in Hararghe and Central highlands of Ethiopia and estimates the link between food security measures. Using the major indicators, food security situation of rural households was very low or poor, $57.3 \%$ of them suffering from food insecurity problems, primarily dependent on staples for their food energy source, and consuming on a few number of food groups. Food security problems were significantly different across farming systems and household idiosyncrasy. Households in Central highlands were relatively better-off in their daily calorie intake and food security status, while they were worse-off in their dietary diversity level and status.

The daily calorie intake and dietary diversity scores of households were positively interdependent, verifying the expectation that households with better dietary diversity were able to have better diet quantity. The simultaneous estimation of household daily calorie intake and dietary diversity scores suggested that the most important determinants of daily calorie intake were female heads, family size, literacy status, total cultivated land, irrigation water use, quantity of fertilizer used, participation in offfarm activity, road distance, and other exogenous shocks. On the other hand, dietary diversity was determined by female heads, literacy status, irrigation water use, live- stock holding, annual income, farming system, and other exogenous factors. On average, households obtained about $1878.7 \mathrm{kcal}$ per day per adult equivalent and consumed only 6.8 number of food items a week, with significant difference by farming systems in which the households operate.

Households' food security status was determined by female heads, cultivated land, quantity of chemical fertilizer used, annual gross income, access to credit, family size, land allocated to staples, and irrigation water use. The likelihood of households to be food secure was $42.3 \%$ with largely different probabilities and marginal effects among farming systems, irrigation water use, and credit access. Households' dietary diversity status, on the other hand, was determined by literacy statuses, livestock holding, annual income, farming system, and the constant term. The probability of households to have semi-diversified diet was $37.2 \%$ with significant difference between farming systems and literacy status of household heads. The bivariate probit estimation of food security status and dietary diversity status of households suggested that these two nonlinear measures were not strongly and significantly interdependent. Accordingly, it is imperative to design appropriate food security intervention strategies since households are more likely to fail in achieving these two-pronged objectives because of limited resource endowments, marketing problems, and other exogenous shocks.

Very important policy implications are derived from this study. One of the basic problems of developing countries like Ethiopia is lack of budge to assess food security situations of households. Estimation of diet quantity available to households is costly, cumbersome and more susceptible to misreporting. The positive linear interdependence between diet quantity and diet diversity is an important evidence to employ cost-effective method of assessing food security situations in Ethiopia. Because dietary diversity of households is associated with their calorie intake, the government can initiate extensive and rapid food security assessment schemes with limited budget in order to formulate and implement relevant food security policies, strategies, and programs. Monitoring of effectiveness of such food security programs will also be cost-effective if dietary intake method of food security analysis is employed.

Idiosyncratic features were significantly influencing food security status of households. Family size was strongly and adversely affecting food security status which necessitates accelerated policy interventions in family planning in order to lessen its negative effects. Literacy status, on the other hand, was an important characteristic feature of household heads in improving daily calorie intake and scale and status of dietary diversity. The current effort in Ethiopia to have educated farmers will have to improve households' calorie supply and dietary diversity in the long run. However, it is also vital to 
promote adult education in order to improve positive nutritional effects of literacy of farm household in the short run. Moreover, households in the two farming systems have strongly and significantly differentiated socioeconomic characteristic features and other unobserved heterogeneities which would influence their food security situations differently. This is a strong empirical evidence to suggest the need to formulate policies and strategies which should take into account these differentials. Policies related to household food security should incorporate these idiosyncratic features and spatial covariate changes in order to achieve food security objectives in different farming systems of the country.

Land allocation pattern of households was adversely and strongly affecting their food security condition. But quantity of chemical fertilizer used was significantly enhancing food security of households. Promoting and supporting smallholders to make optimal land allocation decision and to use production inputs like fertilizer will further improve household food availability through increased production and productivity. Asset holdings were also important factors influencing diet quality dimensions of household food security, calling the need to improve physical and financial asset holdings through income diversification interventions.

\section{ACKNOWLEDGMENTS}

The authors wish to express their sincere acknowledgements to the Swedish International Development Cooperation Agency (SIDA) and Ethiopian Strategy Support Program (ESSP-II) of the Ethiopian Development Research Institute (EDRI) and International Food Policy Research Institute (IFPRI) for their financial support.

\section{REFERENCES}

Abebaw S, Janekarnkij P, Wangwacharakul V (2011). Dimensions of food insecurity and adoption of soil conservation technology in rural areas of Gursum district, eastern Ethiopia. Kasetsart J. (Soc. Sci) 32:308-318.

Adane T (2009). Impact of Perennial Cash Cropping on Food Crop Production and Productivity. Eth. J. Econ. 18(1):1-34.

Bogale A, Shimelis A (2009). Household level determinants of food insecurity in rural areas of Dire Dawa, Eastern Ethiopia. AJFAND 9(9):1914-1926.

Berhanu A (2004). The food security role of agriculture in Ethiopia. eJADE 1(1):138-153.

Birhanu G, Adane H, Kahsay B (2007). Feed marketing in Ethiopia: results of rapid market appraisal. Addis Ababa, Ethiopia.

Birhanu G, Moti J (2010). Commercialization of smallholders: Does market orientation translate into market participation? ILRI (International Livestock Research Institute), Addis Ababa, Ethiopia. Birthal PS, Joshi Pk, Thorat A (2007). Diversification in Indian agriculture towards high-value crops: The role of smallholders. Available http://www.ifpri.org/sites/default/files/publications/ifpridp00727.pdf, accessed October 20, 2012.
Bickel G, Nord M, Price C, Hamilton W, Cook J (2000). Guide to measuring household food security. United States Department of Agriculture (USDA), USA.

Block S, Webb, P (2001). The dynamics of livelihood diversification in post-famine Ethiopia. Food Policy 26(4):333-350.

Brown T, Teshome A (2007). Implementing policies for chronic poverty in Ethiopia. Addis Ababa, Ethiopia.

Cameron AC, Trivedi TK (1998). Regression Analysis of Count Data. Cambridge: Cambridge University Press.

Cameron AC, Trivedi TK (2009). Microeconometrics Using Stata. StataCorp Ld, USA.

De Luca G (2008). SNP and SML estimation of univariate and bivariate binary-choice models. Stata J. 8:190-220.

Dercon S, Hoddinott J (2009). The Ethiopian rural household surveys 1989-2004: Introduction. FPRI, Addis Ababa, Ethiopia.

FANTA (Food and Nutrition Technical Assistance) (2006). Developing and validating simple indicators of dietary quality and energy intake of infants and young children in developing countries: Summary of findings from analysis of 10 data sets (available at www.fantaproject).

FAO and WHO (1985). Energy and protein requirements. Technical Report Series 724. Geneva.

FAO (2007). Guidelines for measuring household and individual dietary diversity. Rome, Italy.

FAO (1996). World food summit plan of action (available at www.fao.org).

FDRE (Federal Democratic Republic of Ethiopia) (1996). Food Security Strategy. Addis Ababa, Ethiopia.

FDRE (2004). Food Security Program 2004-2009. Addis Ababa, Ethiopia.

FDRE (2012). Ethiopia's Progress towards eradicating poverty: An interim report on poverty analysis study (2010/11). MoFED. Addis Ababa, Ethiopia.

Freihiwot F (2007). Food security and its determinants in rural households in Amhara Region. Ethiopian Development Research Institute (EDRI), Addis Ababa, Ethiopia.

Getahun A (1980). Agro-climates and agricultural systems in Ethiopia. Agricultural Systems, 5(1): 39-50.

Greene WH (2012). Econometric Analysis ( $7^{\text {th }}$ Edition). New Jersey: Pearson Hall. pp. 292-293.

Guush B, Zelekawork P, Kibrom T, Seneshaw T (2011). Foodgrain consumption and calorie intake patterns in Ethiopia. Available at http://img.static.reliefweb.int/sites/reliefweb.int/files/resources, accessed on July 9, 2012.

Hadleya C, Linzerb DA, Tefera B, Abebe G, Fasil T, Lindstrome D (2011). Household capacities, vulnerabilities and food insecurity: Shifts in food insecurity in urban and rural Ethiopia during the 2008 food crisis. Soc. Sci. Med. 73:1534-1542.

Hailu M (2012). Causes of Household Food Insecurity in Rural Boset Woreda: Causes, Extent and Coping Mechanisms to Food Insecurity. LAP LAMBERT Academic Publishing.

Hardin JW (1996). Bivariate probit models. Stata Technical Bulletin Reprints, College Station, TX: Stata Press. 6:152-158.

Hendriks SL, Msaki M (2009). The impact of smallholder commercialization of organic crops on food consumption patterns, dietary diversity and consumption elasticities. Agrekon, 48(2):184199.

Hoddinott J, Yohannes $Y$ (2002). Dietary diversity as a food security indicator. FANTA 2002, Washington, DC. (available at http://www.aed.org/Health/upload/dietarydiversity.pdf, accessed 12/07/2012: 4:25 am).

Hoddinott J (1999). Choosing outcome indicators of household hood security. IFPRI, Washnigton, D.C, USA.

Kennedy G, Ballard T, Dop M (2011). Guidelines for measuring household and individual dietary diversity. FAO, Rome.

Langat BK, Ngéno VK, Sulo TK, Nyangweso PM, Korir MK, Kipsat MJ, JS, Kebenei JS (2011). Household food security in a commercialized subsistence economy: A case of smallholder tea famers in Nandi south district, Kenya. J. Dev. Agric. Econ. 3(5):201-209.

Long JS, Freese J (2005). Regression Models for Categorical Dependent Variables Using Stata. $2^{\text {nd }}$ edition, Stata Press, USA.

Long JS (1997). Regression Models for Categorical and Limited 
Dependent Variables (RMCLDV), Thousand Oaks, CA: Sage Press. Maddala GS (1983). Limited-Dependent and Qualitative Variables in Econometrics. Cambridge, Cambridge University Press.

Mamo G, Assefa A, Degnet A (2009). Determinants of smallholder crop farmers' decision to sell and for whom to sell: Micro-level data evidence from Ethiopia. In: Getnet Alemu and Worku Gebeyehu (eds), Proceedings of the Ninth International Conference on the Ethiopian Economy, Addis Ababa, Ethiopia. pp. 47-76,

Maxwell S, Frankenberger T (1992). Household Food Security: Concepts, Indicators, and Measurements. A Technical Review. UNICEF/IFAD.

Maxwell D (1996). Measuring food insecurity: The frequency and severity of coping strategies. Food Policy 21:291-303.

MoFED (Ministry of Finance and Economic Development) (2006). Ethiopia: Building on Progress: A Plan for Accelerated and Sustained Development to End Poverty (PASDEP), Addis Ababa, Ethiopia.

Moti J Gardebroek C (2008). Crop and market outlet choice interactions at household level. Eth. J. Econ. 7(1):29-47.

Radimer K, Olson C, Campbell C (1990). Development of indicators to assess hunger. J. Nutr. 120:1544-1548.

Ruel MT (2002). Is dietary diversity an indicator of food security or dietary quality? A review of measurement issues and research needs. Food Consumption and Nutrition Division Discussion Paper 140, IFPRI, Washington, D.C.
Ruel MT (2003). Operationalizing diet diversity: A review of measurement issues and research priorities. J. Nutr. 133(11):3911S3926S.

Samuel G (2004). Food insecurity and poverty in Ethiopia: Evidence and lessons from Wollo. Ethiopian Economics Association (EEA) Working Paper No. 3/2004, Addis Ababa, Ethiopia.

Samuel G, Sharp K (2007). Agricultural commercialization in coffee growing areas of Ethiopia. Eth.J. Eco., 16(1): 89-118.

Smith LC, Subandoro A (2007). Measuring Food Security in Practice. IFPRI, Washington, D.C.

Swindale A, Ohri-Vachaspati $P$ (2005). Measuring household food consumption: A technical guide. FANTA Project, Academy for Educational Development (AED), Washington, D.C.

Uraguchi ZB (2012). Rural income transfer programs and rural household food security in Ethiopia. J. Asian Afri.Stud., 47(1):33-51.

World Bank (2008). Agriculture for Development. World Development Report 2008, The World Bank. Washington, DC.

Zegeye T, Hussien H (2011). Farm households' food insecurity, determinants and coping strategies: The case of Fadis district, eastern Oromia, Ethiopia. Eth. J. Agric. Econ. 8(1):1-35.

Zellner A (1962). Further properties of efficient estimators in seemingly unrelated regression equations. Int. Econ. Rev. 3:300-313. 